\title{
On the Delamination of FeCrAl ODS Alloys
}

\author{
J. Chao, C. Capdevila-Montes, J. L. González-Carrasco \\ Department of Physical Metallurgy, Centro Nacional de Investigaciones Metalúrgicas \\ (CENIM), Consejo Superior de Investigaciones Científicas (CSIC), Avda. Gregorio del \\ Amo, 8, 28040 Madrid, Spain
}

\begin{abstract}
Tensile specimens tested at room temperature in the rolling direction present clear delamination, but only incipient delaminations was found in specimens tested in transverse direction. Delamination was a strain rate-controlled process and its morphology depends on the processing history, concluding that the cause of delaminations is the embrittlement induced by the hydrogen occluded during processing. Delamination had a small influence on the mechanical properties in the rolling direction. However, a drop in ductility was detected in the transverse direction particularly for the material in the aged condition.
\end{abstract}

Keywords: FeCrAl Oxide Dispersion Strengthened Alloys; Delamination; Processing; Hydrogen embrittlement; Anisotropy 


\section{INTRODUCTION}

Delamination, splitting, separation or fissuring are the terms often used to describe the propagation of brittle cracks parallel to the conforming direction of the material.

Recently it was observed that delamination may occur during tensile test of the as-hot rolled PM 2000 alloy (trade mark of PLANSEE), being the effect more intense in specimens aged at $475^{\circ} \mathrm{C}$ [1]. The delamination event was found to be a strain rate controlled process and has a small influence on the tensile properties [1]. Interrogations on the origin of the delamination and the influence on this event of strain rate and micrfostructural features were the reason for this investigation.

The driving force for delamination was either the transverse stress necking-induced in tensile specimens [2], the transverse stresses notch (crack) induced in Charpy (fracture toughness) tests $[3,4]$, or the longitudinal shear in torsion tests [5]. The microstructural features responsible of delamination of mild/ high strength low and medium carbon steels proposed in the literature, include: decohesion induced by flattened inclusions or of axial inclusions stringers [6-8]; sulphur segregation and grain growth at the centre line [9]; intergranular decohesion induced by sheets of carbides [10-11]; intergranular failure associated to grains with a high aspect ratio [12-14]; anisotropy in plastic properties associated with elongated microstructures [15]; transgranular cleavage texture $(\{100\}<110>)$-induced $[16-18]$; incompatibility of plastic strain at the boundary between $\{111\}$ and $\{100\}$ grain colony [19]; grain boundary weakened by cold working $[3,20-21]$. More recently, it has been argued that the alignment of cementite particles along the high angle grain boundaries promotes the formation of delaminations in ultrafine C-Mn steel processed by warm deformation and annealing [22].

Delaminations in fully pearlitic steels have been also observed in the as-drawn and in the as-drawn plus aged states $[5,23]$. Although a lot of efforts have been devoted to 
determine the microstructural cause of the delamination in this material class, clear conclusion has not been still reached. On the other hand, it was also found in these materials that electrolytically introduced hydrogen assists to the delamination of the material since delamination increases as the hydrogen concentration was increased [24]. This means that hydrogen occlusion can be strongly anisotropic depending on the microstructure of the material, as it was previously reported already for other steel types [25-27].

This paper analyzes the phenomenon of the delamination in tensile tests of PM 2000 alloy under two conditions that might be relevant for room temperature applications. An as-received fine grain size condition, that remains stable after thermal oxidation, [28], and an aged condition $\left(475^{\circ} \mathrm{C}\right)$ that is known to increase tensile and fatigue properties [1]. For completeness, MA 956 alloy (trademark INCOLOY) was also investigated in both the as-received condition and the recrystallized condition $\left(1330^{\circ} \mathrm{C} / 1 \mathrm{~h}\right)$, that is a standard microstructure for high temperature applications. Rational for the selection of these oxide dispersion strengthened (ODS) alloys relies on the fact that they were processed under different powder metallurgical routes, therefore conclusions about the influence of processing might be obtained.

\section{EXPERIMENTAL PROCEDURE}

PM2000 and MA956 alloys were produced by Plansee Group (Reutte, Austria) and Special Metal Corporation (Hereford, United Kingdom), respectively. The chemical composition of these alloys is presented in Table I. The hydrogen content of the material here analyzed was determined with a LECO RH 404 hydrogen analyzer by the fusion of the sample method in an inert gas. 
Both alloys are processed by a powder metallurgical route involving mechanical alloying in either a shielding atmosphere of hydrogen (PM 2000) or argon (MA 956). After consolidation of powders via hot isostatic pressing, hot rolling or hot extrusion between $1000-1100{ }^{\circ} \mathrm{C}$ was performed to obtain a fully dense material. The PM 2000 and MA 956 alloys were supplied as-hot rolled bars of 35 and $59 \mathrm{~mm}$ diameter, respectively. The aging treatment (only for PM 2000 alloy) consists in a thermal treatment at $475^{\circ} \mathrm{C}$ for $100 \mathrm{~h}$.

Two types of tensile specimens of PM2000 alloy were machined: longitudinal specimens, with $40 \mathrm{~mm}$ gage length and $8 \mathrm{~mm}$ in diameter, and transverse specimens, with $10 \mathrm{~mm}$ gage length and a rectangular cross section of $8 \times 2 \mathrm{~mm}^{2}$. The transverse specimens were machined so that the longitudinal direction of the bar is normal to the width face of the specimen. The tensile tests were carried out at room temperature using two strain rates, namely $5.10^{-5} \mathrm{~s}^{-1}$ and $5.10^{-2} \mathrm{~s}^{-1}$. In order to make comparables the elongation values of longitudinal and transverse specimens it was necessary to apply a correction factor to the elongation values of the transverse specimens because of the difference in the slimness ratio $\left(K=L_{o} / \sqrt{S_{o}}\right.$, where $\mathrm{L}_{\mathrm{o}}$ is the gage length and $\mathrm{S}_{\mathrm{o}}$ is the cross-sectional area) of longitudinal $(\mathrm{K}=5.65)$ and transverse $(\mathrm{K}=2.5)$ specimens. The correction factor was obtained from the Bertella-Oliver equation [29], expressed as:

$$
\frac{\varepsilon_{2}}{\varepsilon_{1}}=\left(\frac{K_{2}}{K_{1}}\right)^{-b}
$$

in which $\varepsilon_{2}$ and $\mathrm{K}_{2}$ and $\varepsilon_{1}$ and $\mathrm{K}_{1}$ are the respective values of elongation and slimness ratio of the different specimens and $b$ is an adjustable parameter. Assuming a value of 0.4 of this parameter [29], the factor to compare elongations of specimens with a 2.5 slimness ratio to those with a 5.65 slimness ratio should be of 0.72 . To obtain the reduction in area of transverse specimens the final area was taken as the area of the 
maximum rectangle inscribed in the minimum cross section of the specimen. Therefore, the calculated reduction in area is an upper limit.

In the case of MA 956 alloy the tension tests were performed at the same strain rates as those used for PM 2000 alloy on longitudinal specimens of $3 \mathrm{~mm}$ in diameter and 15

$\mathrm{mm}$ gage length. This alloy was also tested in the recrystallized state after a heat treatment at $1330^{\circ} \mathrm{C}$ for $1 \mathrm{~h}$.

The microstructure was characterized using standard metallographic techniques. To reveal the fine grained structure of the material, selected samples were polished to a $0.25 \mu \mathrm{m}$ finish using a colloidal silica suspension and observed in a field emission gun scanning electron microscope (FEGSEM) operating at $10 \mathrm{kV}$. Fracture surfaces were examined with a stereomicroscope to obtain a general vision of the fracture. The details of the surface and profile of the delaminations were analyzed in the FEGSEM.

\section{RESULTS AND DISCUSSION}

\section{Microstructure}

In the as-hot rolled condition, PM 2000 and MA 956 alloys present a very elongated and fibrous structure with a weak and a strong $<110>$ fibber texture, respectively [3031]. Regarding PM 2000 Fig. 1 shows an optical micrograph that resembles a cold deformed material. At a higher magnification, Fig. 2, it can be ascertained that the microstructure consists of fine grains of about $1 \mu \mathrm{m}$ in diameter, which are slightly elongated in the longitudinal bar direction.

The aging treatment of PM 2000 produces a decomposition of the supersatured solid solution into Fe-rich $\alpha$ and Cr-rich $\alpha^{\prime}$ phases at a nanometric scale [30].

The microstructure of recrystallized MA 956 alloy consists of a very coarse microstructure of 100-1200 $\mu \mathrm{m}$ in diameter and some centimetres in length [31]. 
Furthermore, the grains present a crystallographic orientation in which the $<111>$ direction of some grains and the $<100>$ direction of another grains are parallel to the bar axis [31].

\section{Tensile properties}

PM 2000 alloy. The Table II sumarizes the results of tensile tests of aged and unaged PM 2000 samples performed in longitudinal and transverse directions at $5.10^{-5} \mathrm{~s}^{-1}$ and $5.10^{-2} \mathrm{~s}^{-1}$ strain rates. It can be observed that the yield strength and ultimate tensile strength in the diametral direction are higher than in the longitudinal direction, irrespectively the strain rate. On the other hand, the elongation values and the reduction in area in the diametral test direction are lower than the corresponding longitudinal values, except in the case of the total elongation for the high strain rate. This anisotropic behaviour of yield strength and ultimate tensile strength is similar to that reported for warm rolled carbon steels [32]. However, it must be remarked that although in the ODS alloys the working temperature of about $\approx 1050^{\circ} \mathrm{C}$ is higher than the warm rolling temperature of the carbon steels of about $\approx 650^{\circ} \mathrm{C}$, the microstructure in the as received condition present a similar banded microstructure. The banded microstructure in the case of PM2000 alloy is therefore the cause of anisotropy in the mechanical properties because only a weak texture was observed. The decrease in the elongations values and in the area reduction in the transverse direction regarding to the longitudinal direction is also similar to that observed in carbon steels in the short-transverse direction regarding to the rolling direction [6].

In general, the effect of an increasing strain rate on tensile properties is to increase the yield strength and ultimate tensile strength and to slightly decrease the elongation and reduction in area [33-34]. This behaviour is also followed by PM2000 alloy except for the total elongation and reduction in area. It is particularly evident in the transverse 
direction of the material in the aged condition, in which ductility properties strongly decrease with strain rate. This behaviour will be clarified below on the basis of the fractographic study carried out later on.

Figure 3 shows the macroscopic appearance of fracture surfaces of longitudinal tensile specimens, revealing a strong area reduction, which are consistent with the large elongation values given in Table II. In the case of the specimens tested at the highest strain rate, Figs. 3.b and 3.d the shape of the necking presents a slight asymmetry. The specimens tested in the lowest strain rate, Figs. 3.a and 3.c, present delamination.

Figure 4 shows for the lowest strain rate the influence of aging treatment on the true stress $v s$ true strain plot and the instant in which necking and delamination events were initiated. In order to detect the beginning of the delamination various tensile specimens were strained at the lowest strain rate very near to the fracture stress and then unloaded. Cross sectional views were prepared by sectioning parallel to the longitudinal axis of specimen. It was not observed evidence of incipient delamination, or transverse cracking at the centre of the necked cross section. It was only observed nucleation of isolated voids in the largest oxide particles in the necked region. The calculated maximum values of radial $\left(\sigma_{\mathrm{rr}}\right)$ and hydrostatic $\left(\sigma_{\mathrm{h}}\right)$ stress components at the minimum cross section versus true strain are also plotted in Fig. 4, to evaluate the possibility of a delamination process necking-induced. These values were calculated in accord with the Bridgman's analysis [35] from the actual values of the flow stress $(\bar{\sigma})$ and the necking profile using the following expressions:

$$
\sigma_{r r}=\bar{\sigma} \ln \left(1+\frac{a}{2 R}\right) ; \quad \sigma_{h}=\bar{\sigma}\left[\frac{1}{3}+\ln \left(1+\frac{a}{2 R}\right)\right]
$$

in which $a$ is the radius of the minimum cross section and $R$ is the curvature radius of the neck. Because the necking induced radial stress is considerably lower (about 350 
$\mathrm{MPa})$ than the ultimate tensile strength of the transverse specimen (1100 MPa, see

Table II), two possible delamination mechanisms are proposed. The first would be associated to the dynamical propagation of a crack from the centre of the specimen at the fracture instant. Once the crack initiates transverse stresses are generated ahead of the crack tip. This crack would propagate to reach a critically embrittled region oriented parallel to the specimen axis, which triggers off the longitudinal cracking. This mechanism is similar to that previously proposed for hydrogen-embrittled pearlitic steels [24].

The second mechanism would be associated with the tensile radial stress generated by the spherical compression pulse that is triggered at the centre of the fracture surface at the fracture instant of the specimen. This idea was proposed by Kolsky [36] to explain the observed longitudinal fracture of a cylindrical specimen when a charge is detonated at the centre of one of the end faces of the specimen. The waves generated by the pulse are reflected by the cylindrical surface of the specimen converging onto the axis so that a very large radial tension stress is built-up in this region. It must be noted that in order to be operative any of the above two mechanisms the material must be critically embrittled, which is enhanced as lowered was the strain rate.

MA 956 alloy. Table III shows the results of tensile tests in the longitudinal direction of MA 956 alloy in the as-received and recrystallized states at $5.10^{-5}$ and $5.10^{-2} \mathrm{~s}^{-1}$ strain rates. Similarly to PM 2000 alloy the $0.2 \%$ yield strength and the ultimate tensile strength increase and the values of elongation and reduction in area decrease as strain rate increases. From the comparison of the values of Table III it appears that the effect of strain rate is more marked in the case of the recrystallized material. However, this comparison can be misleading for this state because the possible differences in crystallographic orientation between specimens and because the specimen material can 
not be considered as a polycrystalline material because the large grain size regarding to the specimen diameter.

Figure 5 shows the macroscopic appearance of the tensile specimens of as-rolled material in which it is clear the effect of the strain rate on the delamination. The fracture appearance is very different from the observed in Fig. 3 of PM 2000 alloy, presumably because the delamination morphology depends on the material processing. At the test temperature of $-196^{\circ} \mathrm{C}$, the effect of the strain rate on the material delamination is fully removed in spite of that considerably plasticity (40\% RA) occurred. In this case longitudinal cracking is not related to the strain rate. Occasional longitudinal cracking occurred, but at both high and low strain rates.

Figure 6 shows the effect of strain rate on the fracture appearance of tensile specimens of the recrystallized material. It is evident the anisotropic nature and the very coarse structure of the grains of the material in this state. Moreover, the fracture aspect is not the usual of the cup and cone type but of the shear type. The delaminations occurred at the lowest strain rate and have a planar morphology running along of the shear planes. Therefore the delamination morphology depends on the deformation mode which in turn depends on the material processing.

\section{Fractographic analysis of PM2000 alloy}

Longitudinal specimens. The fracture mechanism is by nucleation, growth and coalescence of microvoids, i.e ductile type as expected from the results in Table II. Disregarding of the strain rate, it was observed that the average size of the microvoids was about $0.5 \mu \mathrm{m}$. FEGSEM micrographs of the profile and the surface of the delaminations are shown in Fig. 7. From Fig. 7.a it seems that the delamination occurs 
in a brittle mode along the fibbers by almost an intergranular path with some tear ridges. Accordingly, the fracture surface showed in Fig. 7.b does not present cleavage features but it is intergranular. The macroscopic view of the delamination of the aged material in Fig. 8.a and more clearly in Fig. 8.b reveals that it radiates from the centre of the necked cross section of the specimen.

Transverse specimens. Figures 9 and 10 show the fracture surface of the transverse specimens. In the case of the unaged material the fracture surface at the specimen midwide of the specimens tested at the lowest strain rate, Fig. 9.a consists of a mixing of cleavage and intergranular areas separated by incipient part-through thickness delaminations (IPTTD) and by tear ridges features which number decreases at the lateral regions. In the mid-wide of the specimens tested at the highest strain rate the fracture, Fig. 9.b, mainly occurred by coalescence of microvoids whereas the fracture surface in the lateral regions is formed by ductile areas and some cleavage islands separated by IPTTD. Apparently the IPTTD number at the lowest strain rate is higher than in the specimens tested at the highest strain rate.

In the case of the aged material tested at the lowest strain rate, Fig. 10.a, the fracture surface was intergranular mainly with some cleavage facets and numerous IPTTD. The fracture surface, Fig. 10.b, at the specimen mid-wide for the highest strain rate, consists of cleavage areas with some ductile islands which number decreases in the lateral regions. It can be also appreciated a secondary crack and as at the low strain rate case numerous IPTTD.

Some remarkable delamination-related points arise from the above results:

Longitudinal tests

- The necking-induced radial-stress was as much a 20 percent of the axial stress and then it is lower than the ultimate tensile strength in the 
transverse direction. Therefore delaminations were not only necking induced.

- Delamination is a strain rate controlled process

- Morphology of the delaminations depends on the material processing

- Because no trend of delamination with strain rate was observed at $-196^{\circ} \mathrm{C}$ it is likely that delamination at room temperature is induced by a diffusion process of an embrittlement element, presumably hydrogen

- Delamination produces negligible effects on tensile properties.

Transversal tests

- Incipient delamination occurs disregarding of strain rate

- An increase of strain rate produces a notably increase in the ductility, particularly, in the aged material. Such increase, for the unaged material, is accompanied by a change in the fracture mechanism from a mixing of cleavage and intergranular mechanisms to a ductile morphology. In the case of the aged material the change was from a purely intergranular mode to a mixing of ductile-cleavage-intergranular modes.

- Similarly to as occur in carbon steels regarding with hydrogen embrittlement, as higher is the strength level of the material, worse are the ductility properties at low strain rates.

Comparing the ductility values of longitudinal and transversal test at the lowest strain rate it is noticeable the strong directional character of the embrittlement. 


\section{Delamination Mechanism}

The above results have shown that although both factors the transverse stresses necking induced and the microstructural features of the material contribute to the delamination, these can not be considered the main cause because it is a strain rate controlled process. To the authors knowledge no consideration has been previously given to the role of the hydrogen introduced during the processing alloy neither on the delamination nor on the ductility loss associated to its embrittling effect in FeCrAl ODS alloys. However, interesting experimental results of previous work devoted to the pore formation in PM 2000 alloy [37] have already open the door to consider the above possibility.

Effectively, tensile tests performed on PM 2000 alloy under ultrahigh vacuum conditions at room temperature have revealed that in the fracture instant the partial pressures of hydrogen and water vapour increased by about three orders of magnitude and three times respectively regarding to those of a dummy sample [37].

In the case of PM 2000 alloy the hydrogen may have been introduced into the material in two stages of the alloy processing. First, during mechanical alloying (MA) some hydrogen will be dissolved in atomic form by dissociation and adsorption of $\mathrm{H}$ shielding gas at the surface of fractures powder particles induced by this stage and another part in molecular form will be trapped in closed pores or cracks resealed during repeated collisions of the powder particles [38]. Second, during the consolidation stage, water vapour can be introduced into the system as adsorbed water vapour on the surfaces of the powder particles. This water vapour reacts at the consolidation temperature $(\approx$ $1050^{\circ} \mathrm{C}$ ) with $\mathrm{Al}, \mathrm{Cr}$ or $\mathrm{Ti}$ to form $\mathrm{Al}_{2} \mathrm{O}_{3}, \mathrm{Cr}_{2} \mathrm{O}_{3}$ or $\mathrm{TiO}_{2}$ respectively [39-40]. Hydrogen can be incorporated into the alloy from the reaction of hydroxides $\left(\mathrm{Fe}(\mathrm{OH})_{2}\right.$ and $\left.\mathrm{Al}(\mathrm{OH})_{3}\right)$ on the powder particles with $\mathrm{Al}[37]$. In the case of MA956 alloy the 
hydrogen mainly can be only incorporated into the material during consolidation stage because Ar gas shielding was used instead of $\mathrm{H}$ as in PM2000 alloy.

The hydrogen content of PM 2000 alloy was determined in three conditions: asreceived; annealed at $1100^{\circ} \mathrm{C}$ for $100 \mathrm{~h}$; annealed $1100 / 100 \mathrm{~h}$ plus aging at $475^{\circ} \mathrm{C}$ for $100 \mathrm{~h}$. For the case of MA956 alloy it was considered the as-received and recrystallized $\left(1330^{\circ} \mathrm{C} / 1 \mathrm{~h}\right)$ states. Five samples were taken for each condition of each material to obtain the hydrogen contents. From the results of the analysis showed in Table IV it is worth noting that the same hydrogen content were obtained in the as-received condition for both alloys in spite of the differences in the gas shielding used during MA. Bearing in mind that the thermal treatment to recover the ductility (i.e. to drive out the hydrogen of the sample) consists in a heating at $200^{\circ} \mathrm{C}$ for $24 \mathrm{~h}$, it is remarkable that only $4 \mathrm{ppm}$ of the hydrogen contained in the ODS ferritic alloys was released from the material after annealing treatments at $1100^{\circ} \mathrm{C} / 100 \mathrm{~h}$ and $1330^{\circ} \mathrm{C} / 1 \mathrm{~h}$. This behaviour has been attributed to the rate of hydrogen production during annealing treatment is compensated by a low hydrogen release because of the low permeability of the micropore wall to hydrogen gaseous [37]. This low permeability occurs because the surface of the micropores is covered with sulphur, which effect is to hinder the hydrogen dissociation which in turn is a necessary step for the hydrogen release [37].

The following mechanism is proposed to explain the delamination and the ductility lost in the transverse direction of FeCrAl ODS alloys. When uniaxial stress is applied hydrogen filled micropores are stretched until the fracture stress of sulphur-rich shell. At that point the hydrogen is able to diffuse out the micropore. The hydrogen begins to concentrate in the region of maximum triaxial stress ahead of dislocation pile-up in grain boundaries until the critical concentration in which embrittlement takes place is reached. Both factors, ductility loss in the transverse direction and delamination would 
be related to the directional nature as well as at the hydrogen occlusivity as at the hydrogen transport during straining which in turn are related to the material microstructure.

\section{CONCLUSIONS}

- Delamination in PM 2000 and MA 956 ODS alloys during tensile test is a strain rate controlled process.

- Delaminations produce no significant changes in the mechanical properties in the rolling direction, however, produce great changes in ductility in the transverse direction, particularly for high strength levels (aged condition).

- The main cause of the delaminations is the hydrogen stored in the material during its processing.

- The morphology of the delaminations depends on the material processing.

\section{ACKNOWLEDGEMENTS}

The authors acknowledge financial support from the Spanish Ministerio de Educación y Ciencia in the form of a Coordinate Project in the Energy Area of Plan Nacional 2006 (ENE2006-15170-C02). In addition one of the authors (J.Ch) gratefully acknowledges the contribution of Ms. C. Peña for help with the fractographic work

\section{REFERENCES}

[1] J. Chao, J.L. González-Carrasco, C. Capdevila, ISIJ Int. 47 (2007) 1214-1220.

[2] A.J. DeArdo, Met. Trans., 8A (1977) 473-486. 
[3] J.D.G. Groom and J.F. Knott, Met. Sci., 9 (1975) 390-400.

[4] W. Guo, H. Dong, M. Lu, X. Zhao, Int. J. Press. Vessels and Piping 79 (2002) 403412.

[5] I. Lefever, U. D’Haene, W. Van Raemdonck, E. Aernoudt,, P. Van Houtte, J.G.

Sevillano, Wire J. Int., Nov. (1998) 90-95.

[6] W.B. Morrison, Metals Technol., Jan. (1975) 33-41.

[7] I. Kozasu and H. Kubota, Trans. ISIJ, 11 (1971) 321-330.

[8] E. A. Almond, Met. Trans., 1, (1970) 2038-2041.

[9] M.M. Salama, J. Offshore Mechanics and Artic Engineering, 126 (2004) 346-349

[10] A.J. McEvily, Jr. and R.H. Bush, Trans. ASM, 551962 655-666.

[11] D.F. Lentz, in A. Marcantonio (Ed.), Mechanical Working and Steel Processing

XII, Dolton, III, Metallurgical Society of AIME, (1974) pp 397-412.

[12] B.L. Bramfitt and A.R. Marder, Met. Trans., 8A (1977) 1263-1273.

[13] B.L. Bramfitt and A.R. Marder, in J.M. Gray (ed), Processing and Properties of Low-Carbon Steel, Metallurgical Society of AIME, (1972) pp 191-224.

[14] D.S. Dablowski, P.J. Konkol and M.F. Baldy, Metals Eng. Quart., Feb. (1976) 2232.

[15] P. Brozzo and G. Buzzichelli, Scr. Mater., 10 (1976) 235-240.

[16] D.N. Hawkins, Metals Technol., Sept. (1976) 417-421.

[17] D.L. Bourell, Met. Trans. 14A (1983) 2487-2496.

[18] H. Inagaki, Z. Metallkd. , 76 (1988) 85-91.

[19] S. Matsuda, Y. Kawashima, in S. Nagashima (Ed), Texture of Materials.

Tokio:ISIJ, 1981, pp659-668.

[20] N.P. Allen C.C. Earley, K.F. Hale and J.H Rendall, Oct. (1964) 808-817.

[21] B. Mintz, W.B. Morrison, Mater. Sci. Technol., 4 (1988) 719-731.

[22] R. Song, D. Ponge, D. Raabe, J.G. Speer, Acta Mater., 53 (2005) 4881-4892.

[23] B.G. Goes, in Universidad de Navarra (Ed). Patentados modificados y

envejecimiento estático y dinámico de alambres de acero perlítico. Memoria inédita presentada para optar al grado de Doctor Ingeniero Industrial. Escuela Superior de Navarra. San Sebastián, 1996. pp 254-255.

[24] D.G. Enos,J.R. Scully, Mater. Trans., 33A (2002) pp 1151-1166.

[25] K. Onishi, , J. Japan Institute of Metals, 34 (1970) 215-221.

[26] Z. Lixin, L. Liguang, Acta Metallurgica Sinica, 18 (1982) 402-410.

[27] H-L. Lee, S. L-I. Chan, Mat. Sci. Eng., A142 (1991) 193-201. 
[28] J.L. González-Carrasco, G. Ciapetti, M.A. Montealegre, S. Pagani, J. Chao and N. Baldini , Biomat., 26 (2005) 3861-3871

[29] J.M. Holt, in H. Kuhn, D. Medlin (Eds) ASM Handbook, vol. 8: Mechanical testing and evaluation. ASM International. Materials Park. Ohio, (2000) pp 124-142

[30] C. Capdevila, M.K. Miller, K.F. Rusell, J. Chao, J.L. González-Carrasco, Mat. Sci. Eng. A (2008) doi:10.1016/j.msea.2008.01.029.

[31] J. Chao, M.C. Cristína, J.L. González-Carrasco, G. González-Doncel, in L. Lecomte-Beckers, F. Schubert, P.J. Ennis (Eds), Proc. Conf. "Materials for Advanced Power Engineering 1998”, II, Forschungzentrum Jülich GmbH. 1998, pp 827-833.

[32] B. Mintz, W.B. Morrison, P.I Welch, G.J. Davies, in G. Gottsein, K. Lücke (Eds), Texture of Materials. 1978, II, Aachen. Germany. Berlin Springer Verlag, (1978) pp 465-473

[33] W. Dahl, in Verein Deutscher Eisenhüttenleute (Ed), Steel. A Handbook for Materials Research and Engineering. 1: Fundamentals, Springer Verlag, Berlin, (1992) pp 203-378.

[34] A.R. Rosenfield, G.T. Hahn, Trans. ASM, 59 (1966) 962-980.

[35] P.W. Bridgman, in Studies in Large Plastic Flow and Fracture, first ed., McGrawHill Book Co., New York.

[36] H. Kolsky, in Stress Waves in solids. Dover Publications, Inc. New York, 1963.

[37] B. Heine, R. Kirchheim, U. Stolz, H. Fischmeister, Powder Metall. Int., 24 (1992) 158-163.

[38] Y.L. Chen, A.R. Jones, U. Miller, Metall. Mater. Trans., 33A (2002) 2713-2718

[39] D. Sporer, W. Lengauer, P. Ettmayer, G. Korb, Powder Metall Int, 23 (1991) 162 165

[40] G. Korb, in E. Artz and L. Schultz (Eds), DGM Conference "New Materials by Mechanical Alloying Techniques”, Deutsche Gesellschaft für Metallkunde, Germany, 1989, pp 175-182 


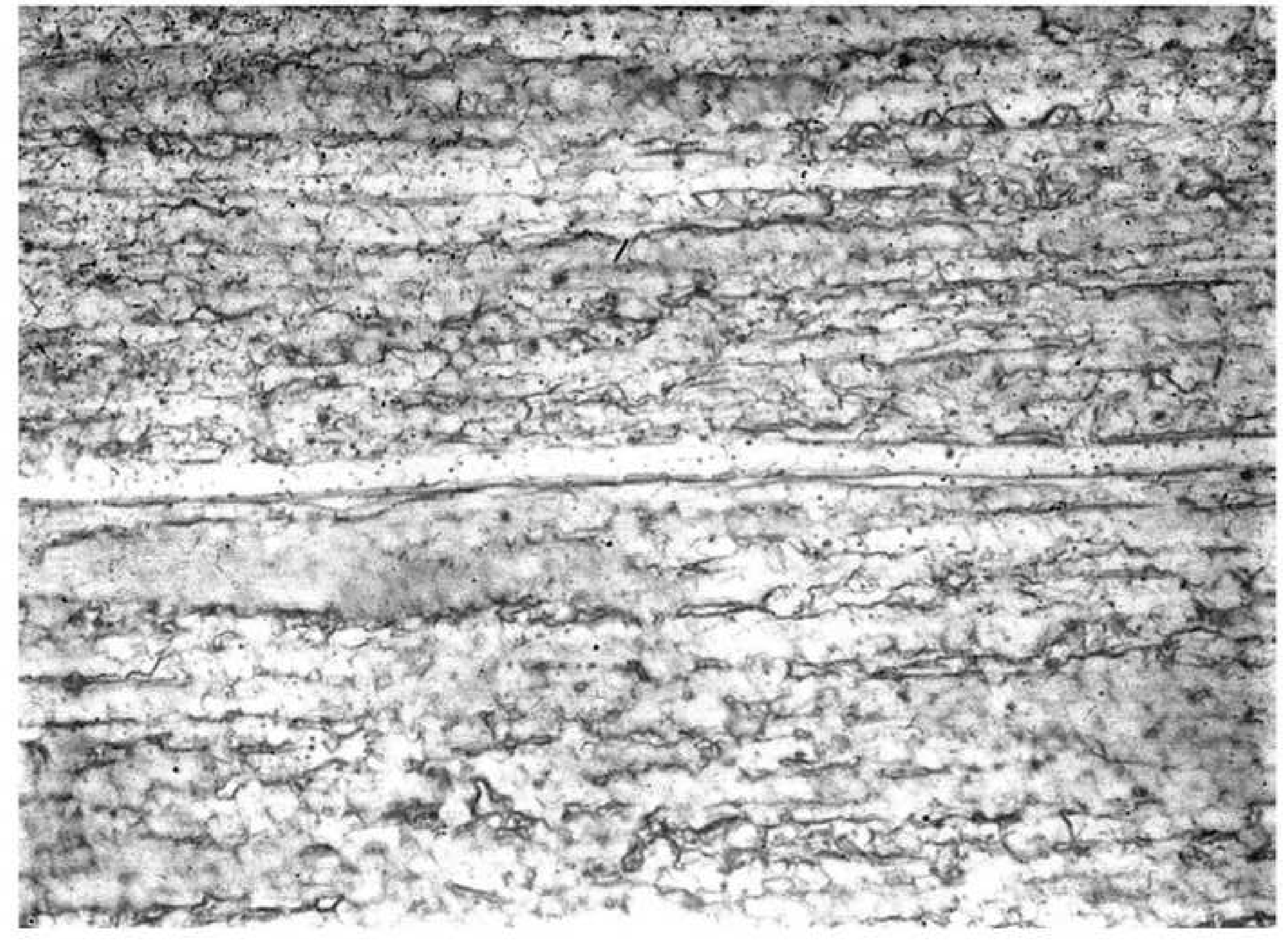




\section{Figure(s)}

Click here to download high resolution image

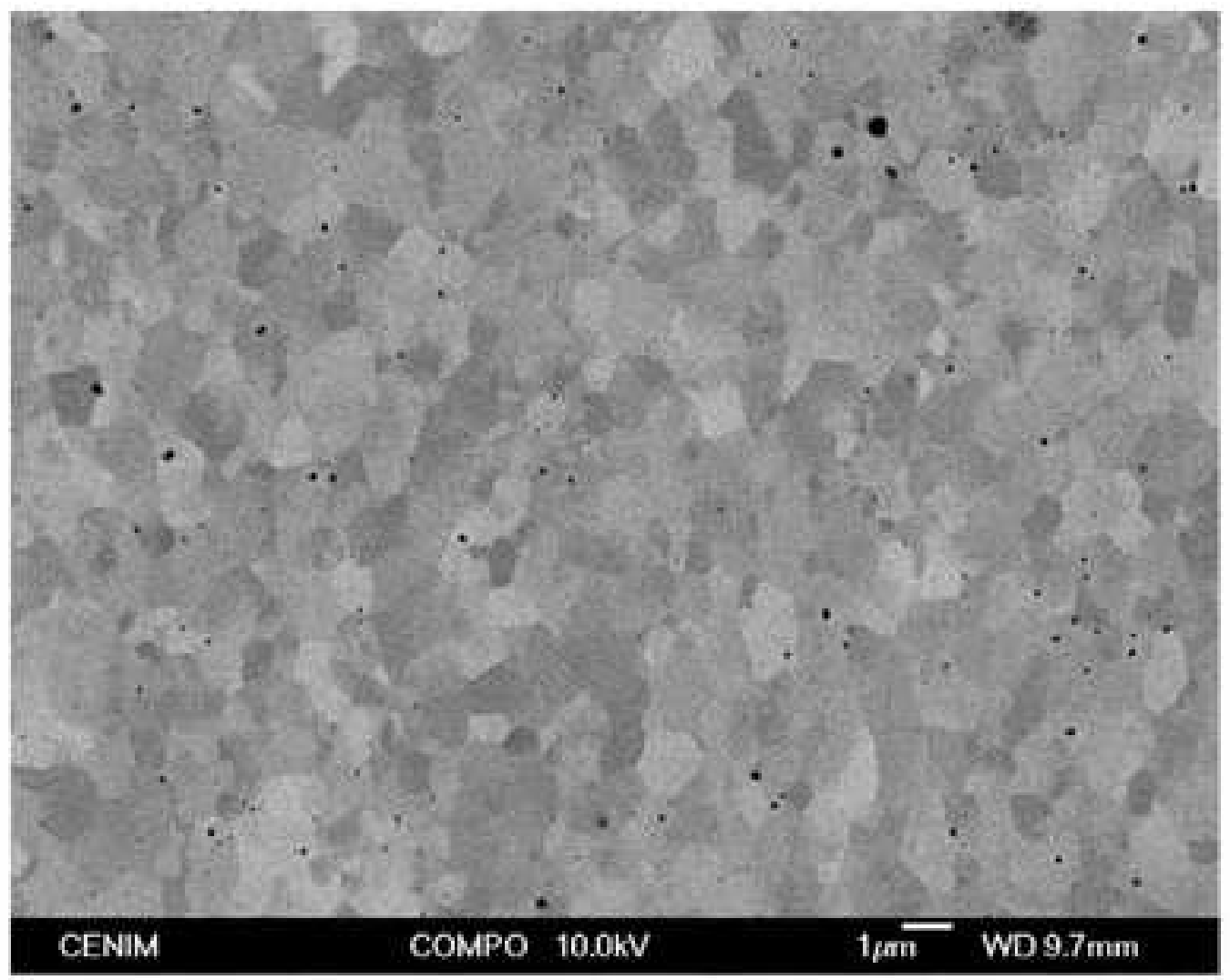

(a)

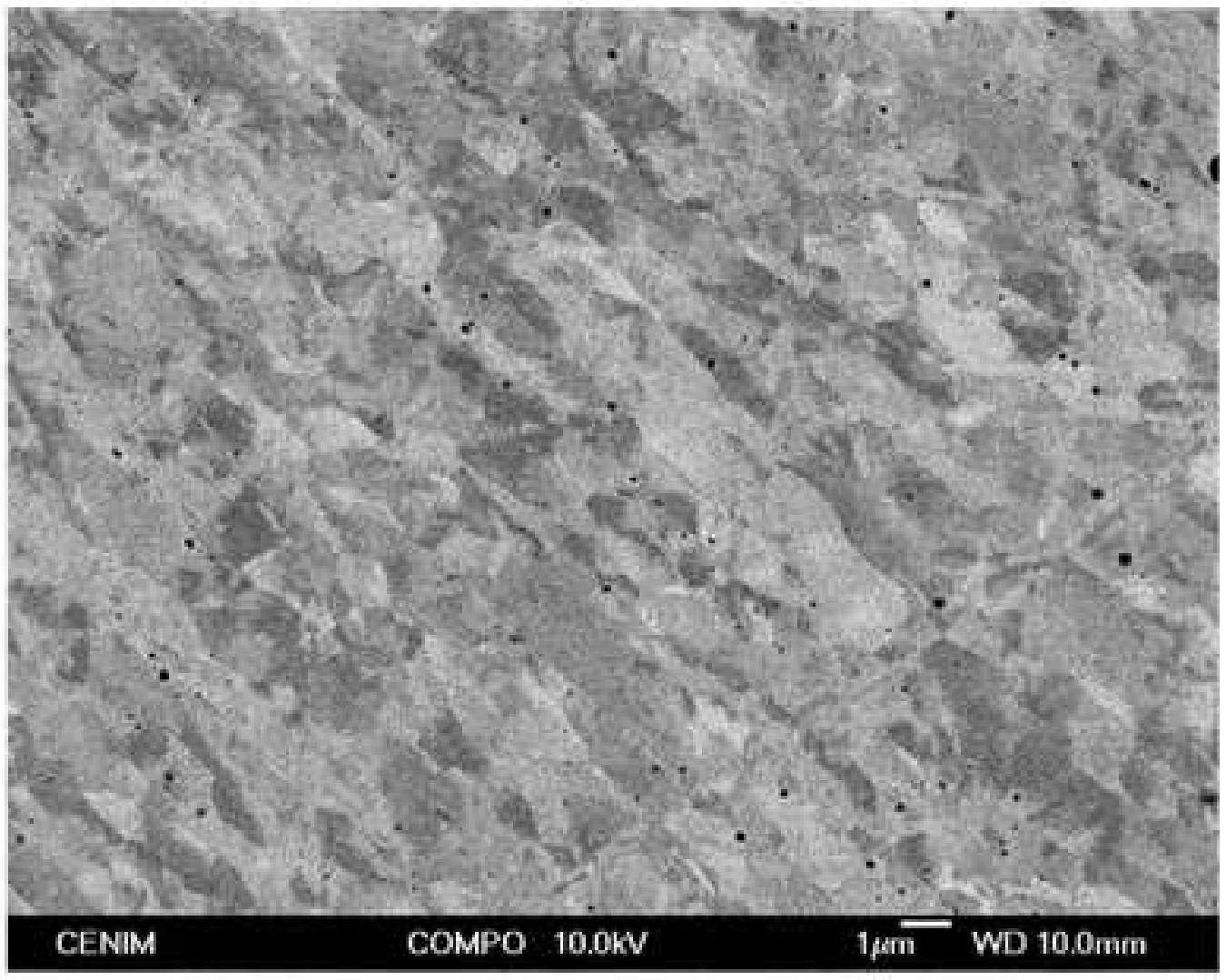

(b) 
Figure(s)
Click here to download high resolution image

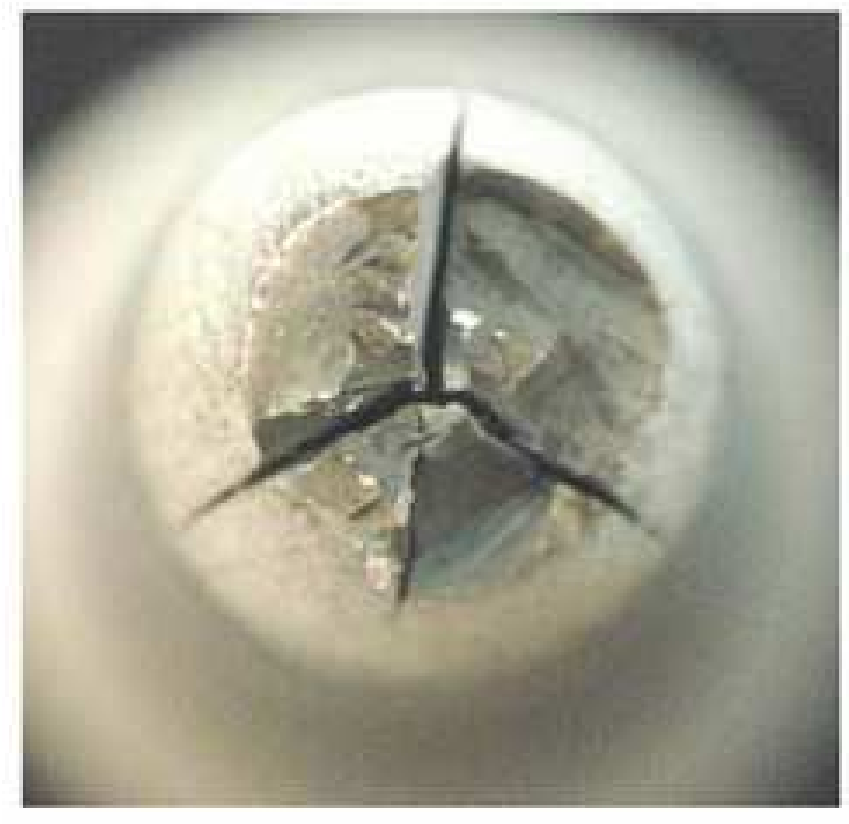

(a)

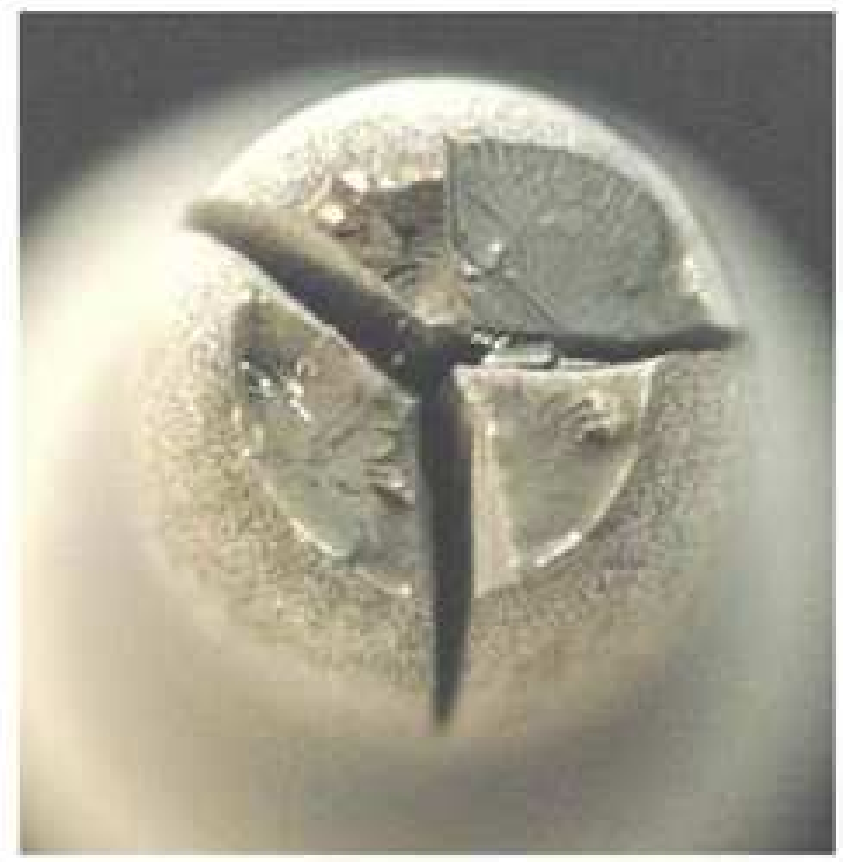

(c)

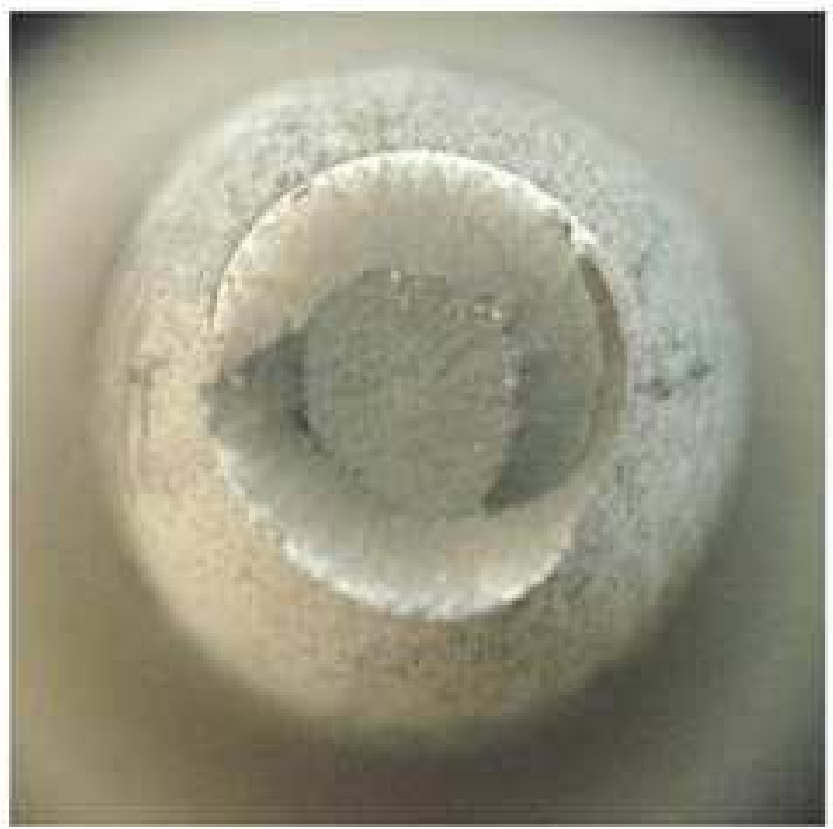

(b)

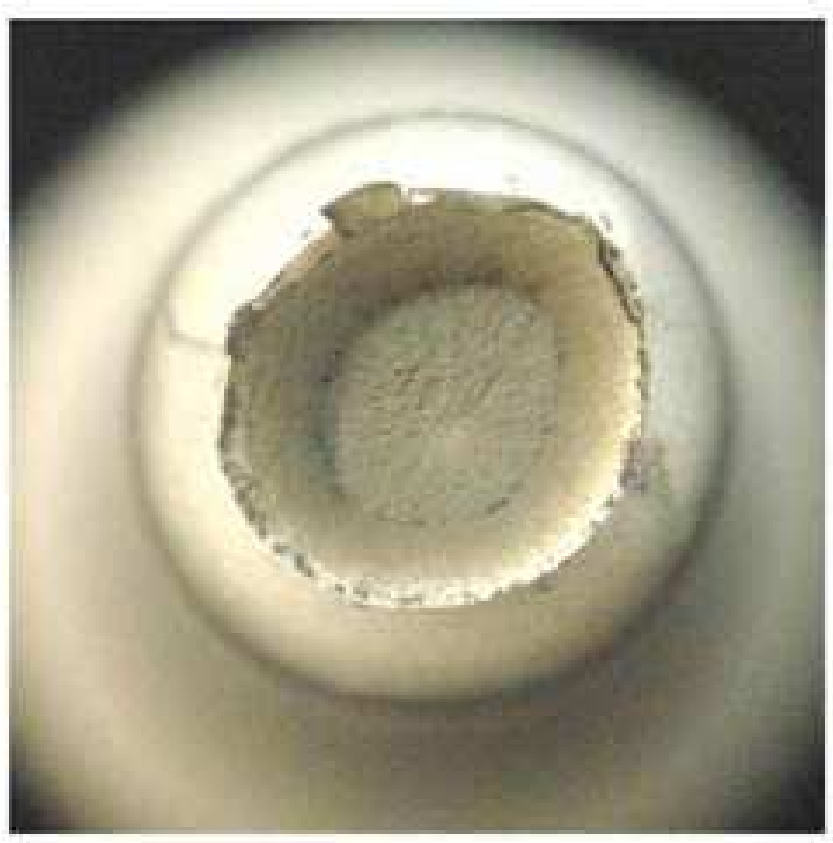

(d) 
Click here to download high resolution image

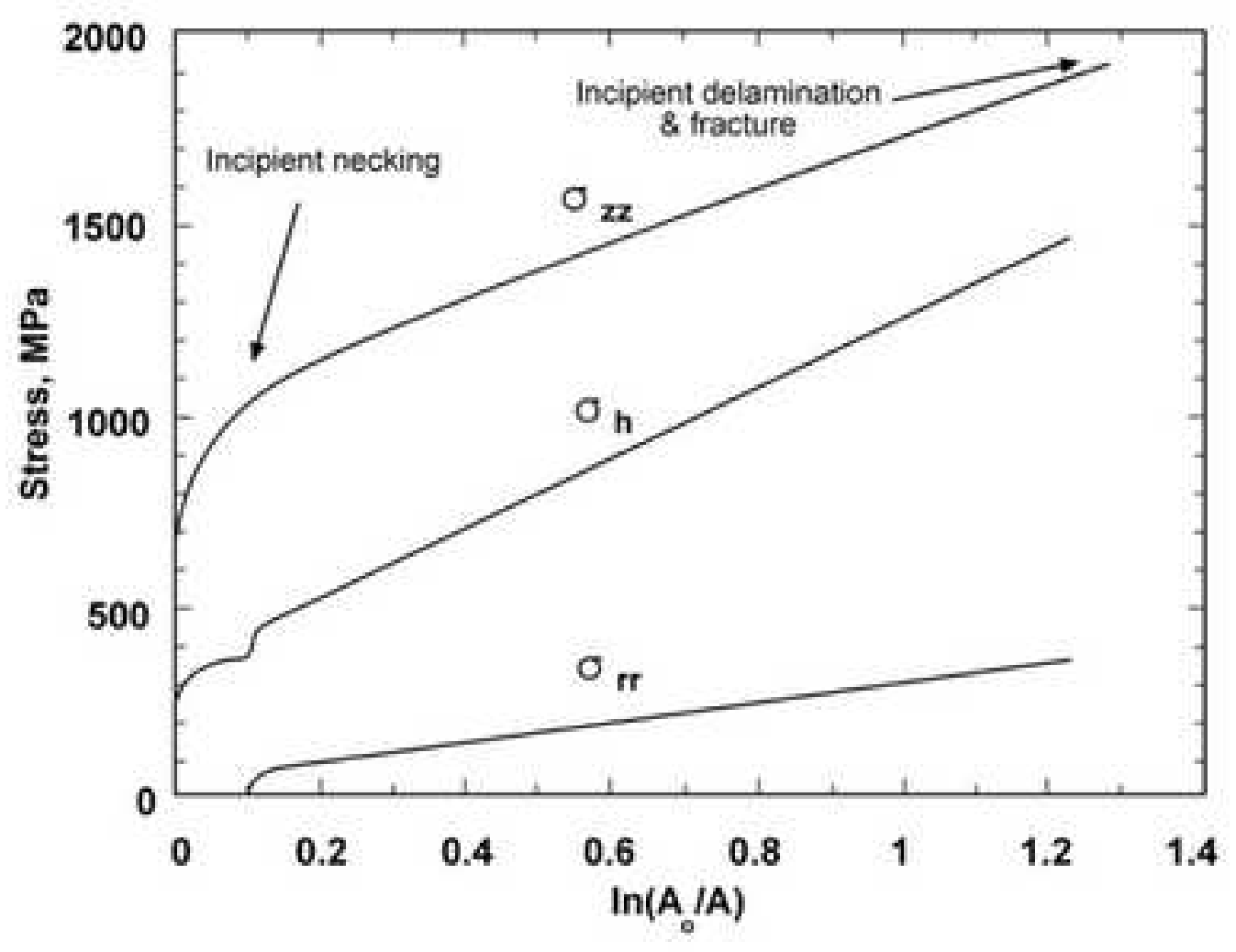

(a)

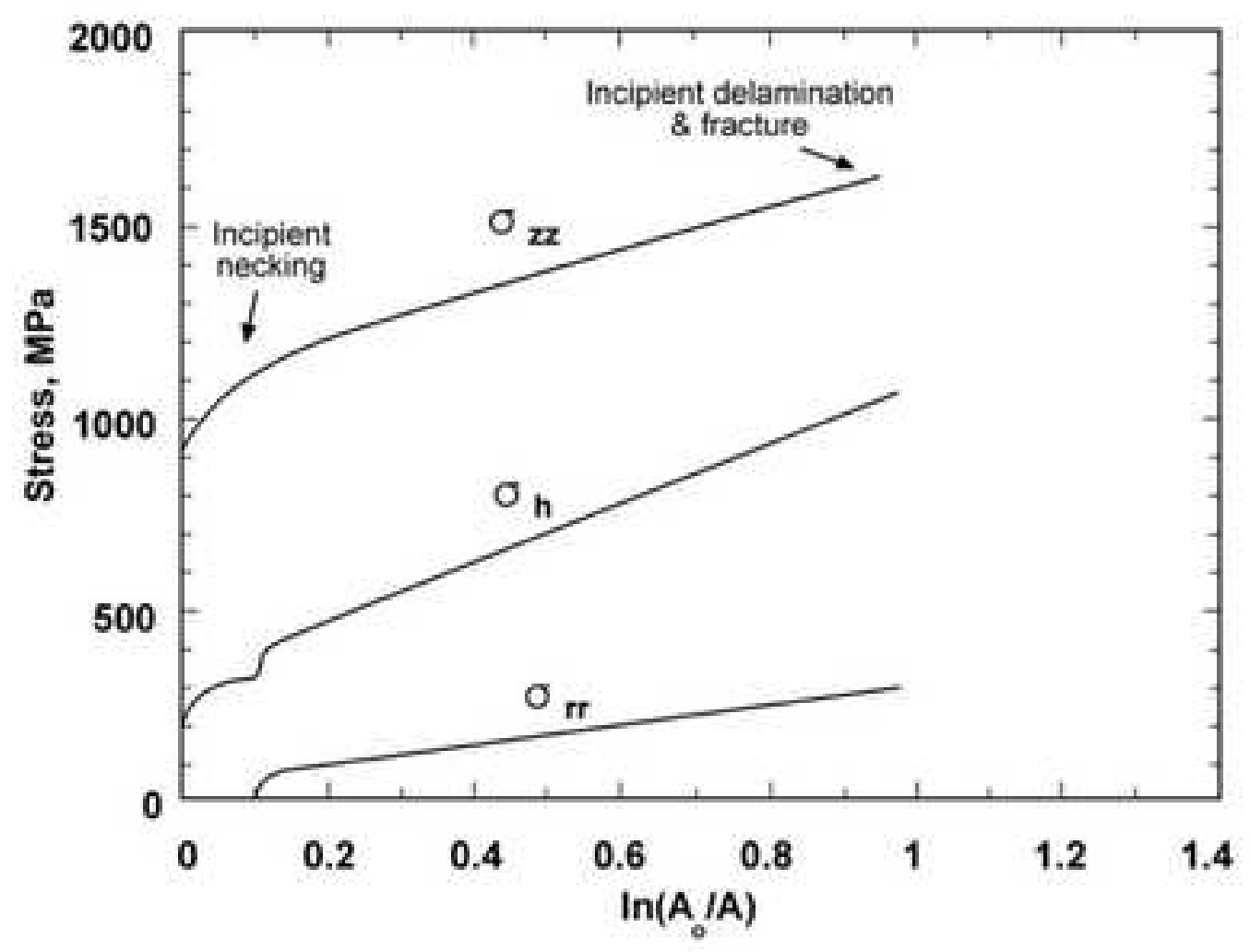

(b) 
Click here to download high resolution image

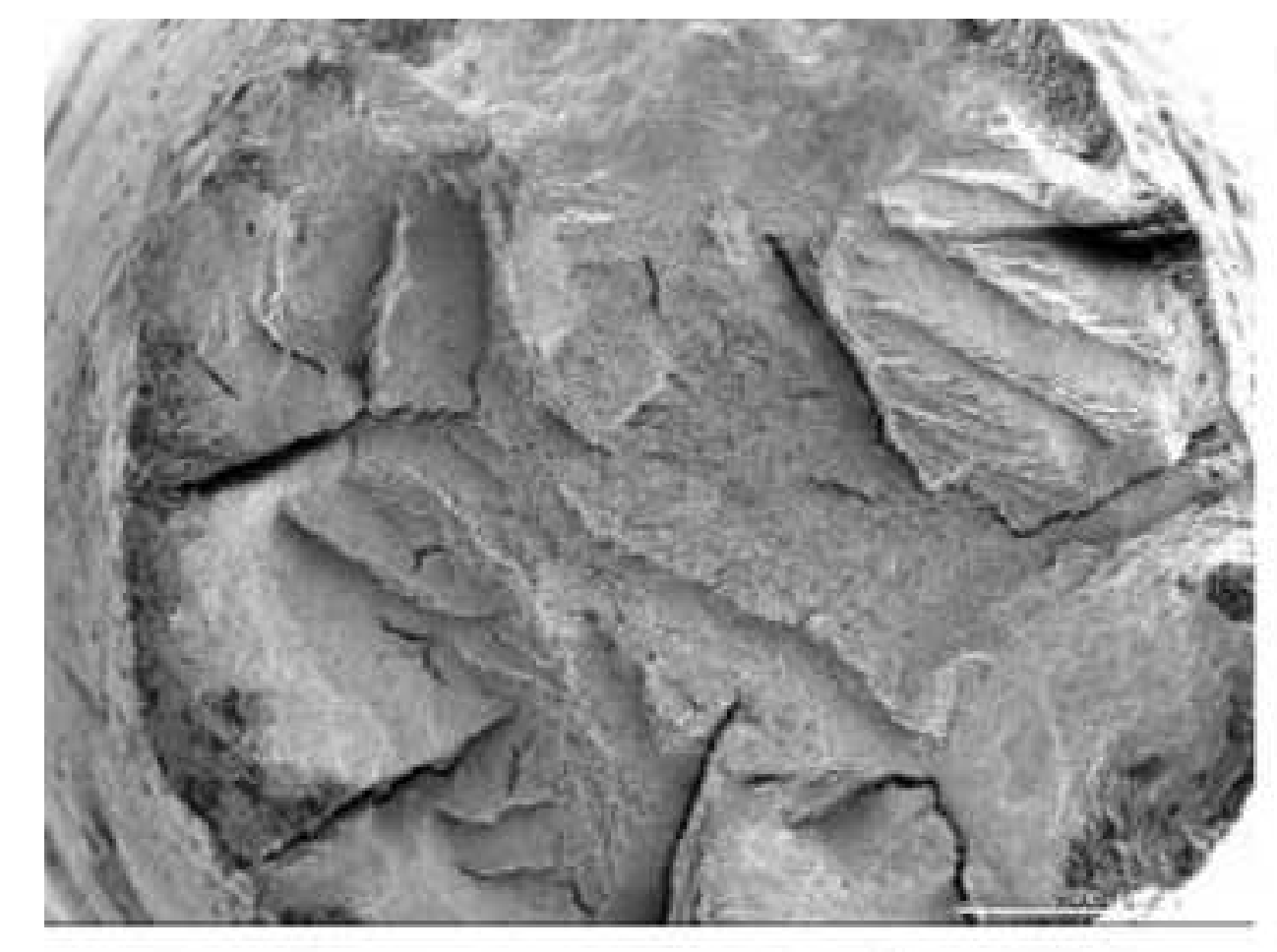

$$
\begin{gathered}
\dot{\varepsilon}=5 \cdot 10^{-5} \mathrm{~s}^{-1} \\
\text { (a) }
\end{gathered}
$$

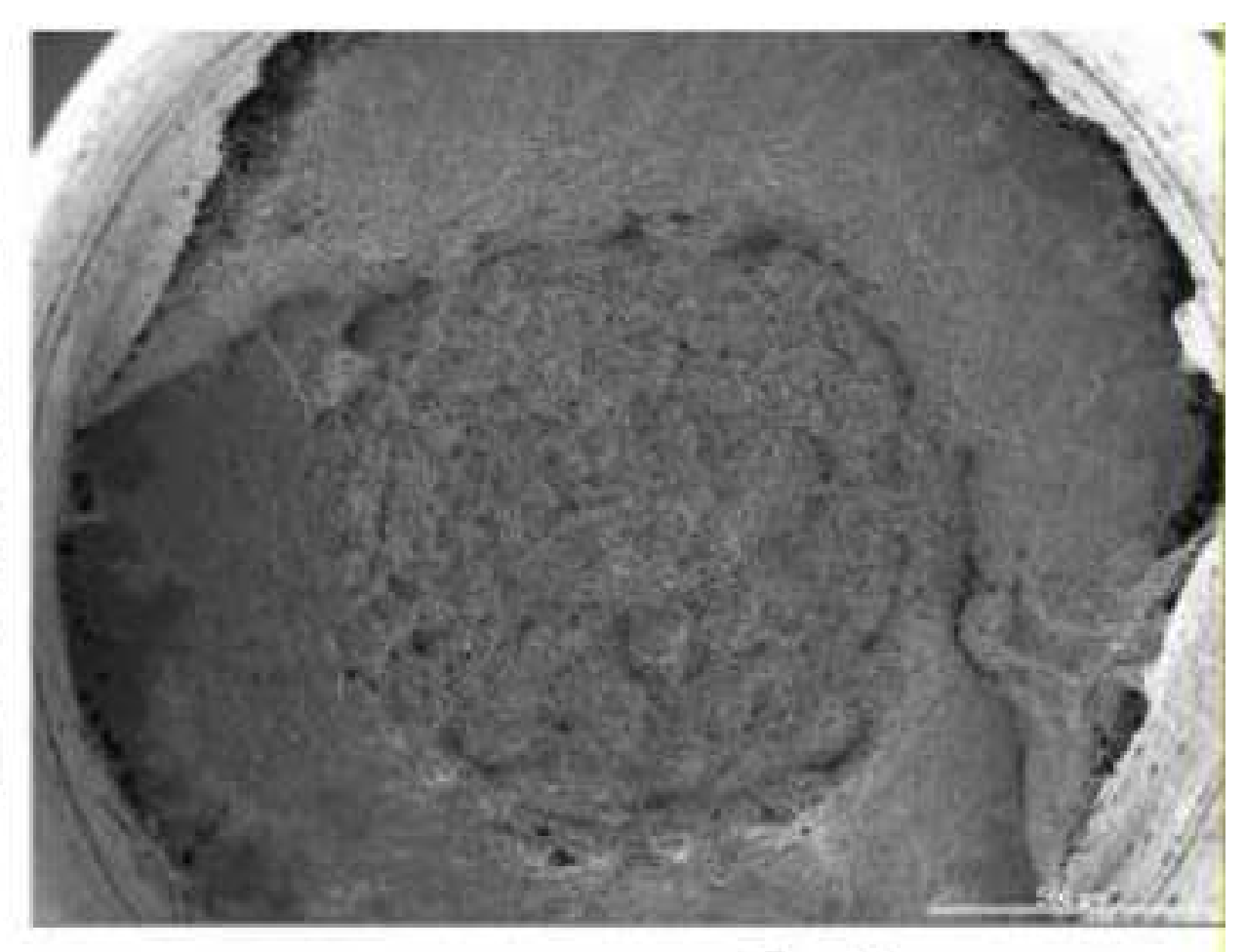

$$
\begin{gathered}
\dot{\varepsilon}=5 \cdot 10^{-2} \mathrm{~s}^{-1} \\
\text { (b) }
\end{gathered}
$$


Figure(s)
Click here to download high resolution image

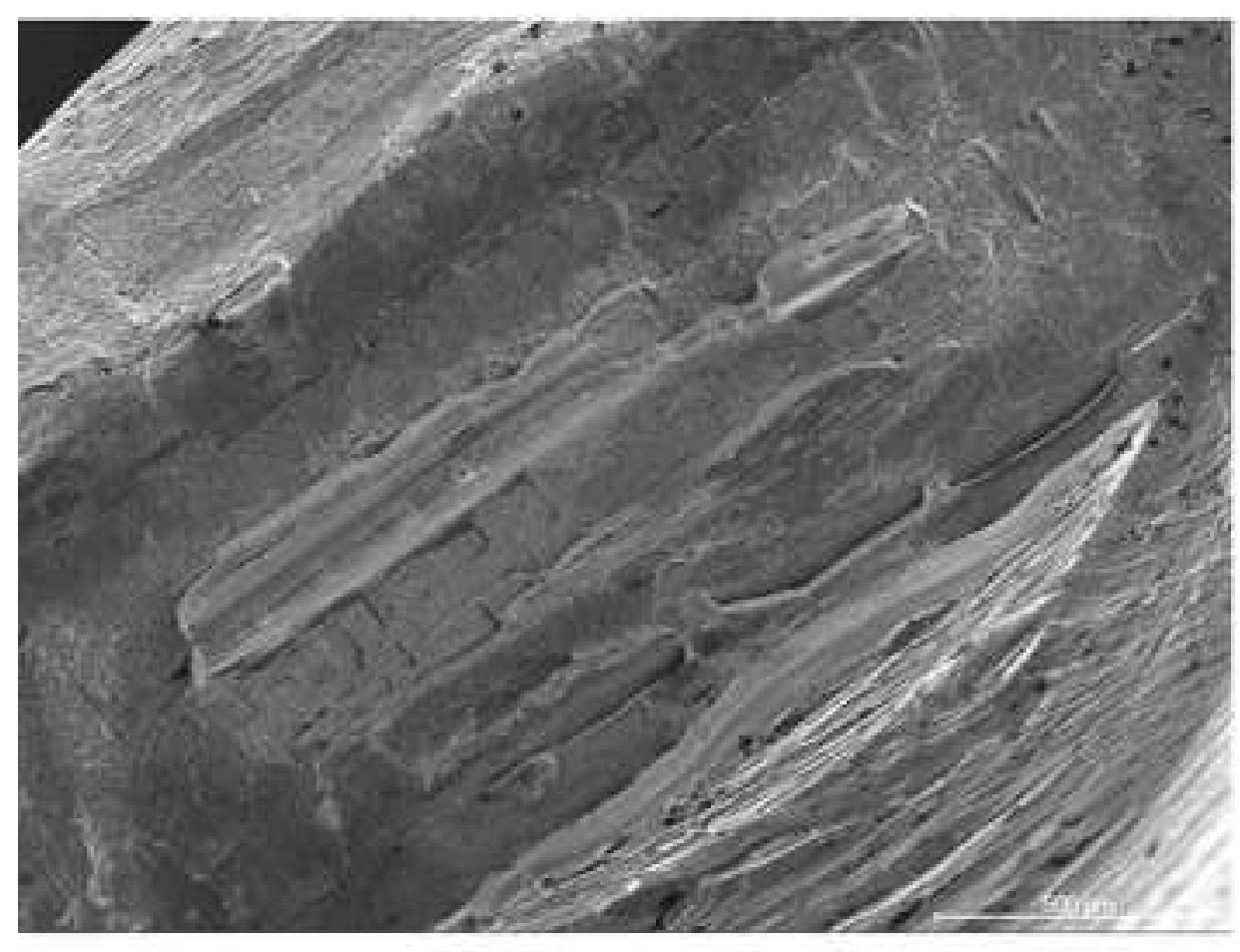

(a)

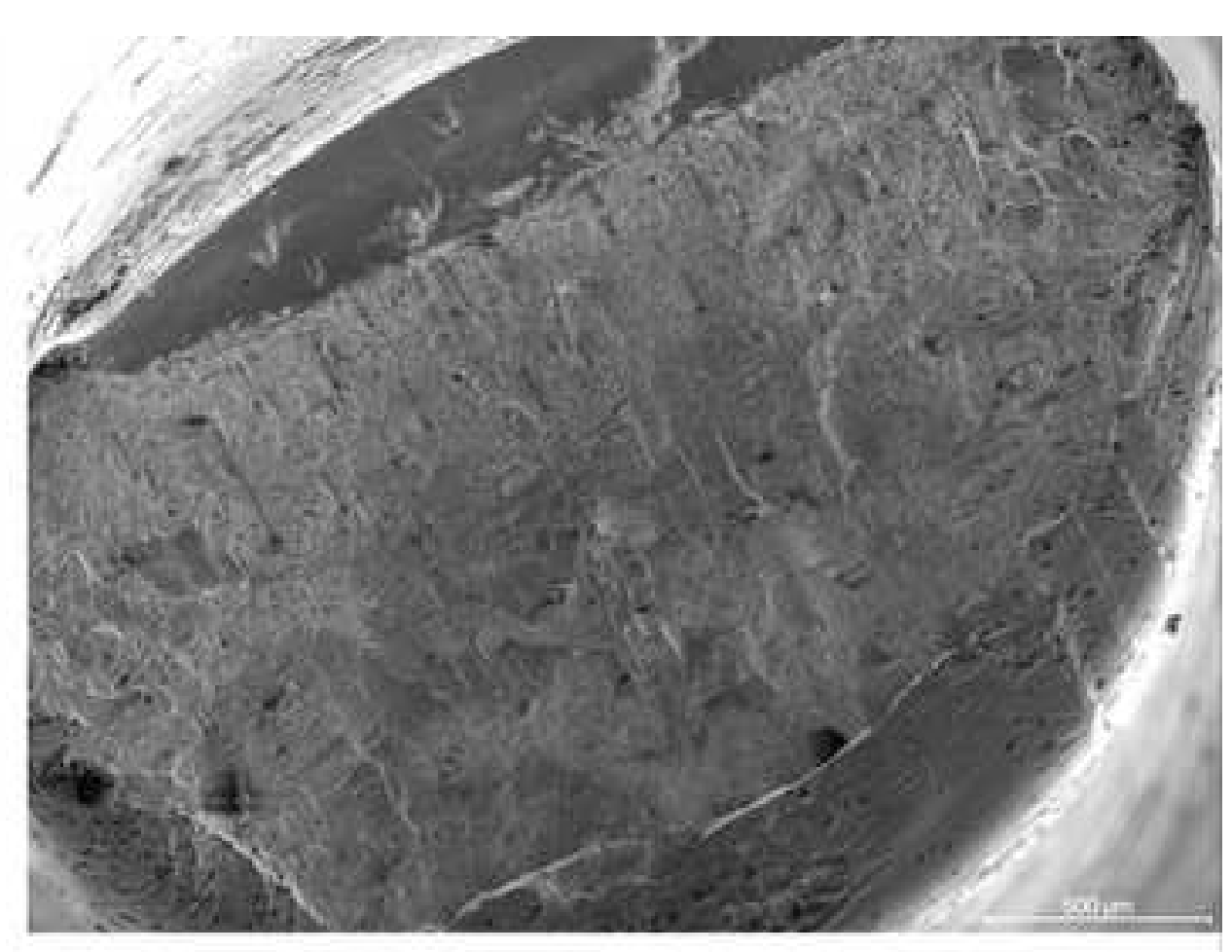

(b)

$$
\text { b) }
$$

Click here to download high resolution image 
Figure(s)
Click here to download high resolution image

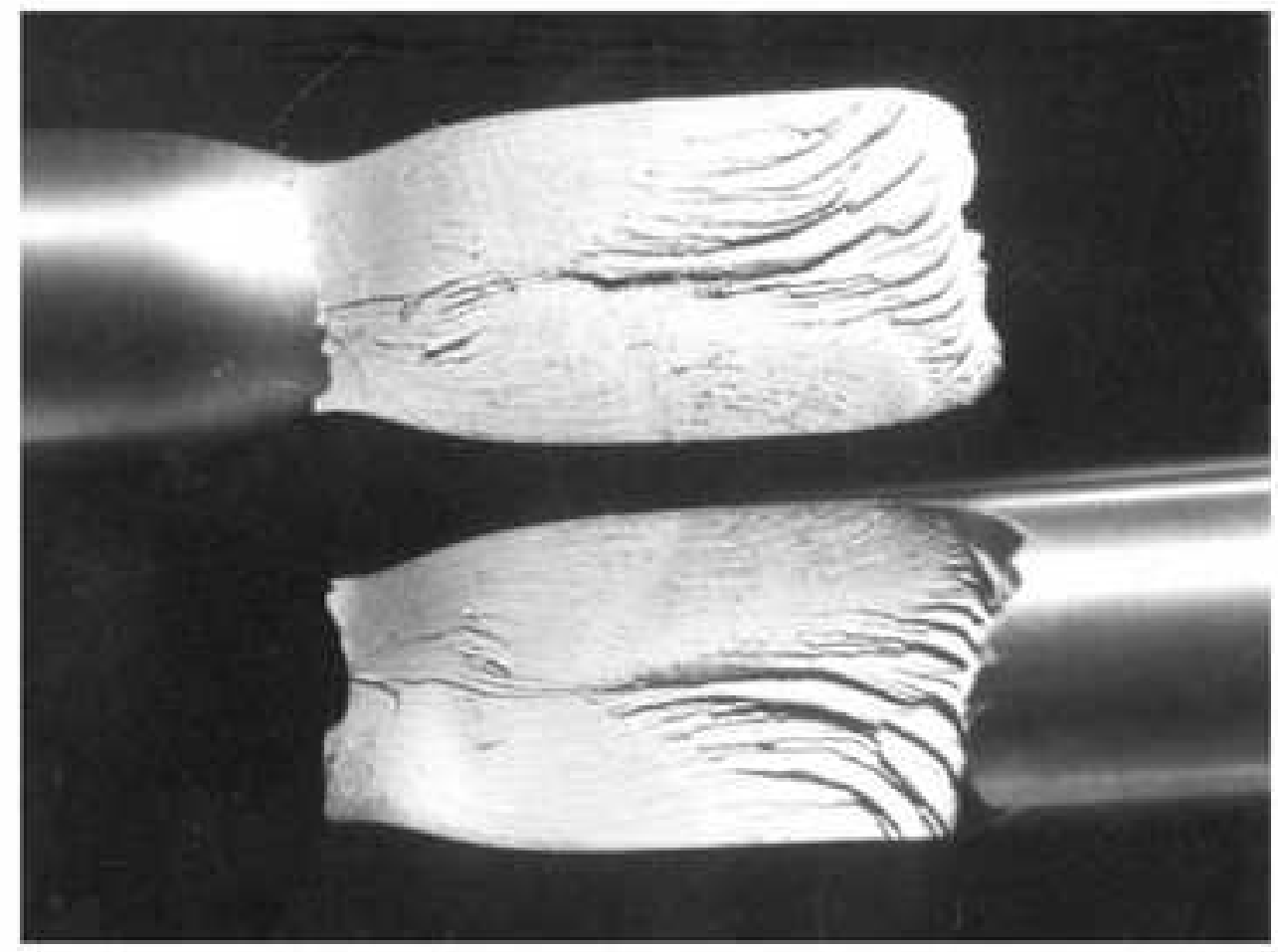

(a)

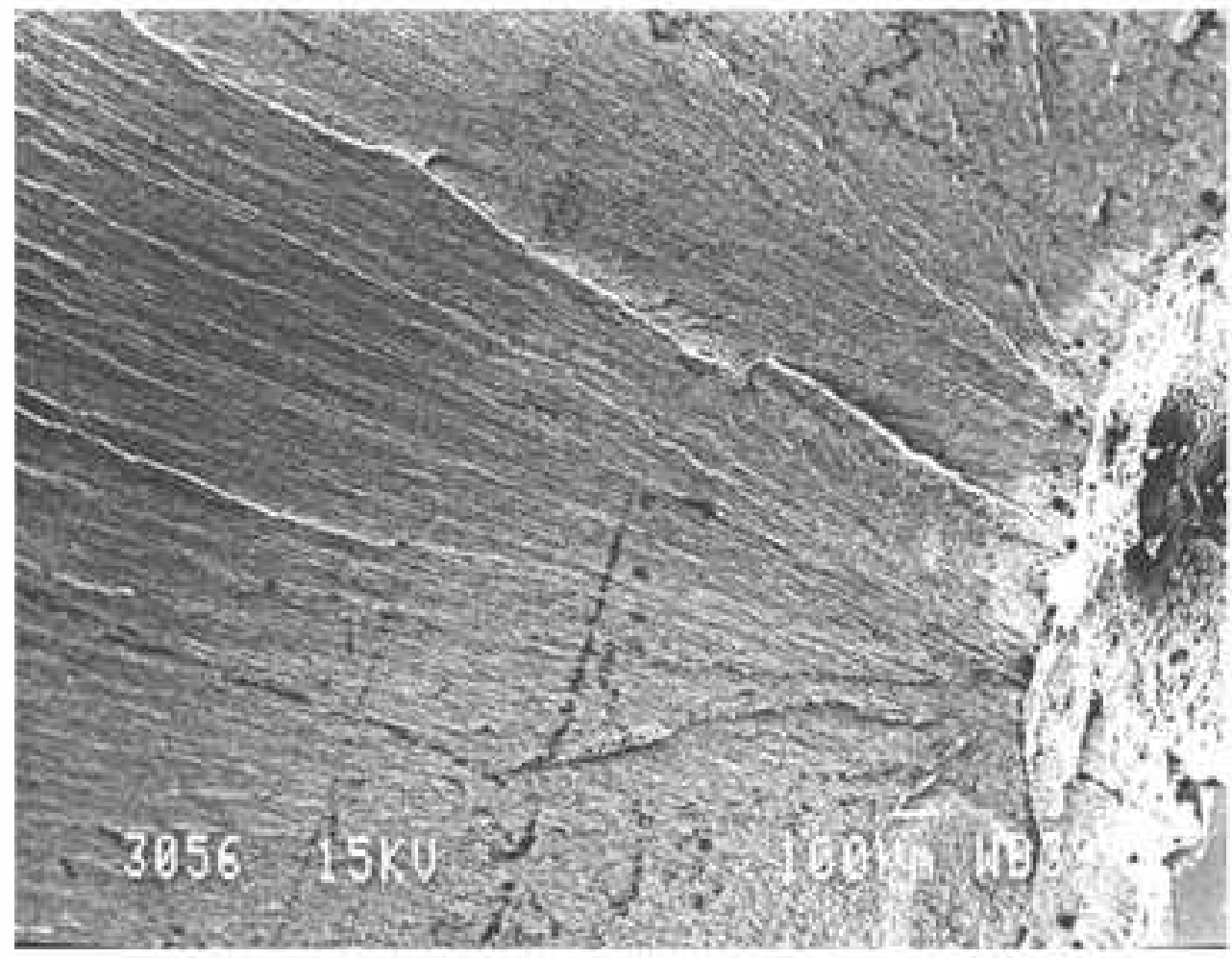

(b) 
Click here to download high resolution image

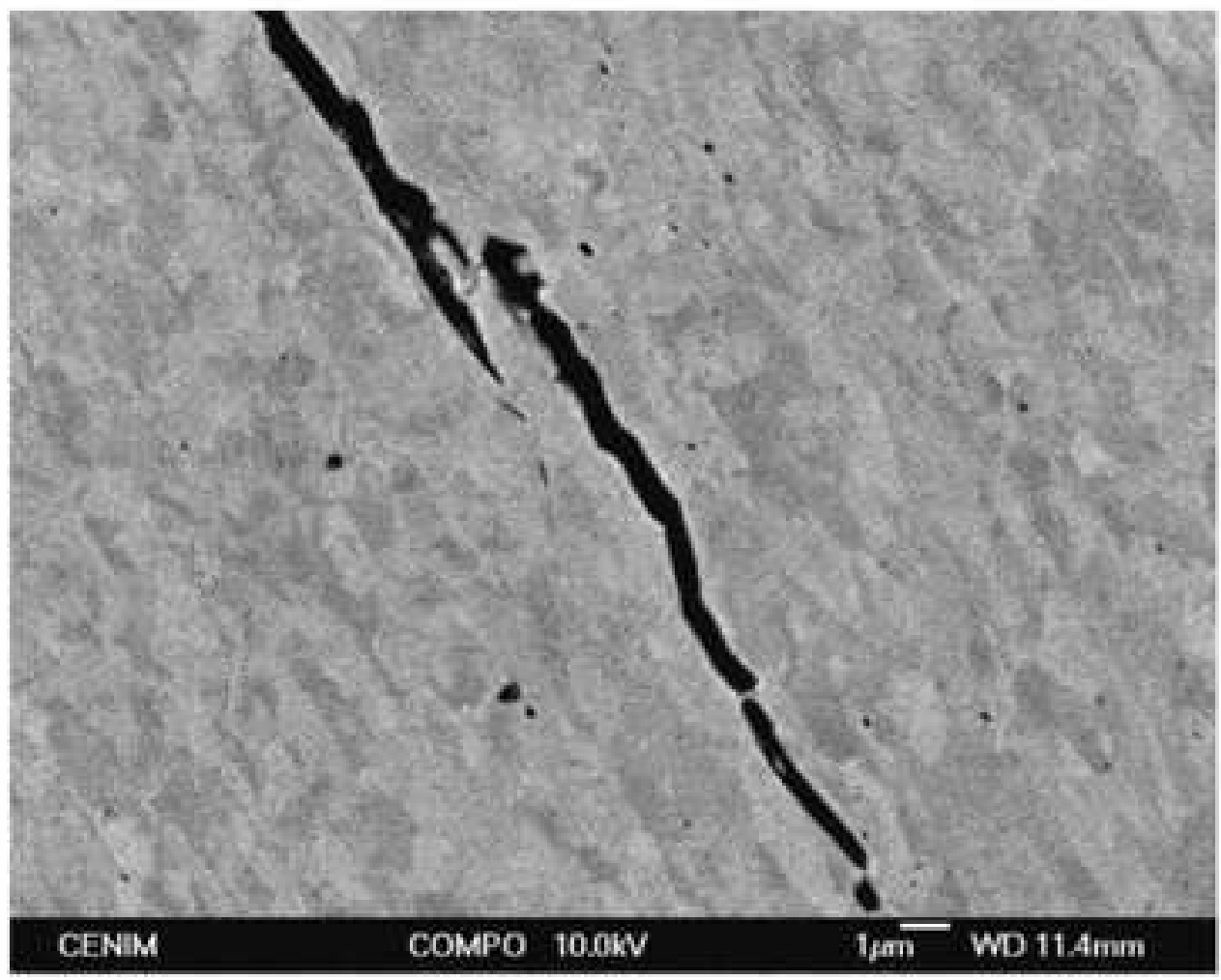

(a)

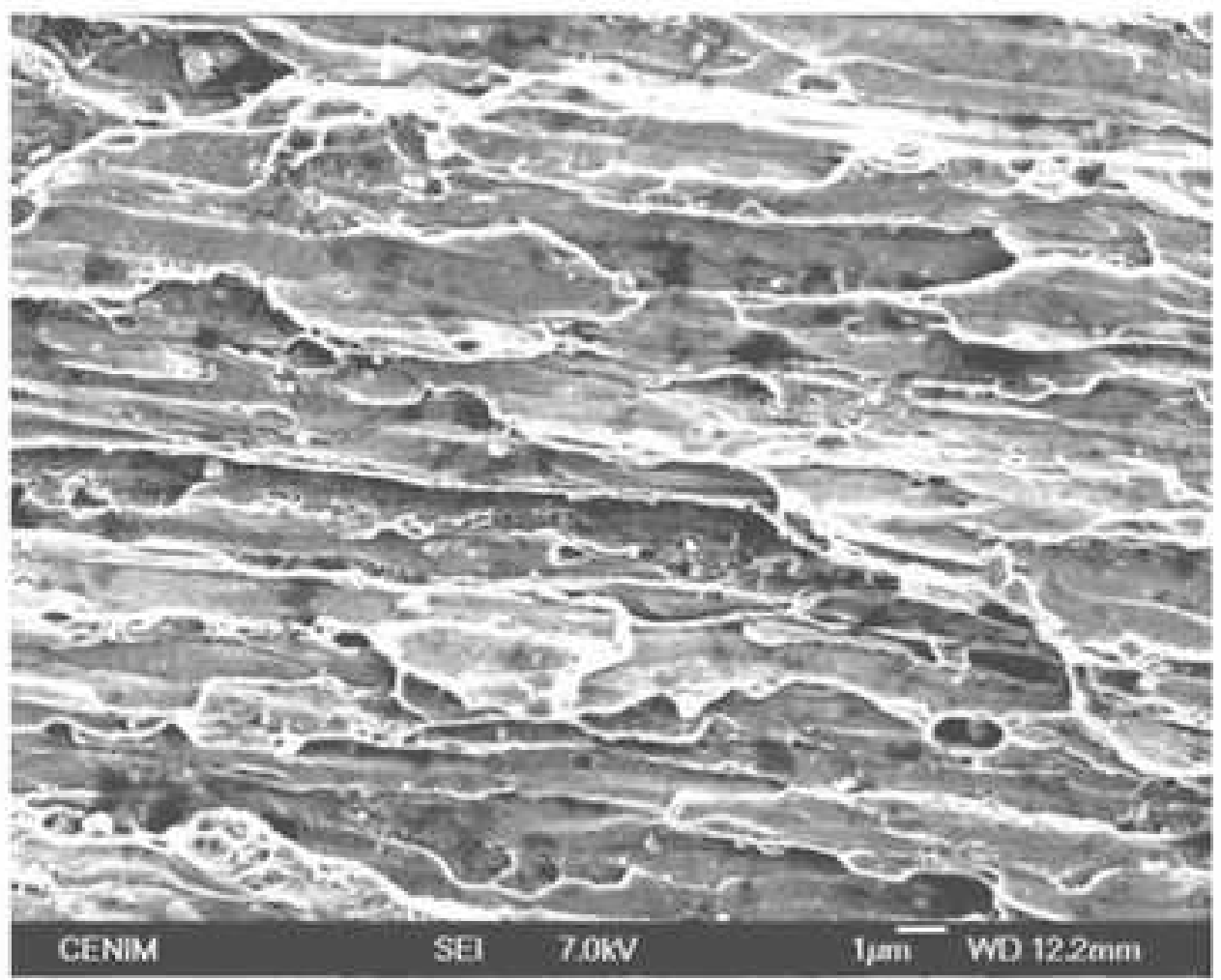

(b) 

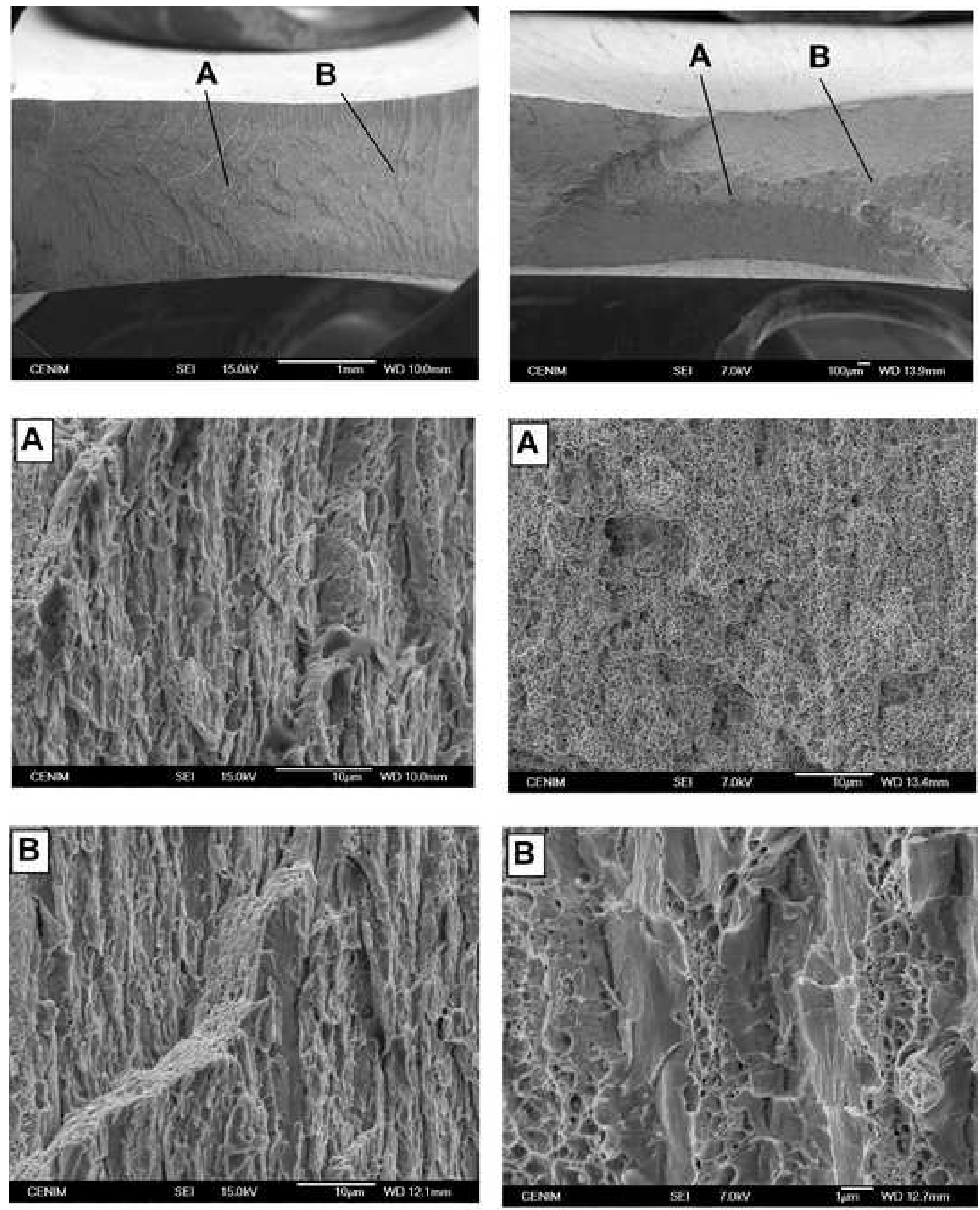


\section{Figure(s)}

Click here to download high resolution image
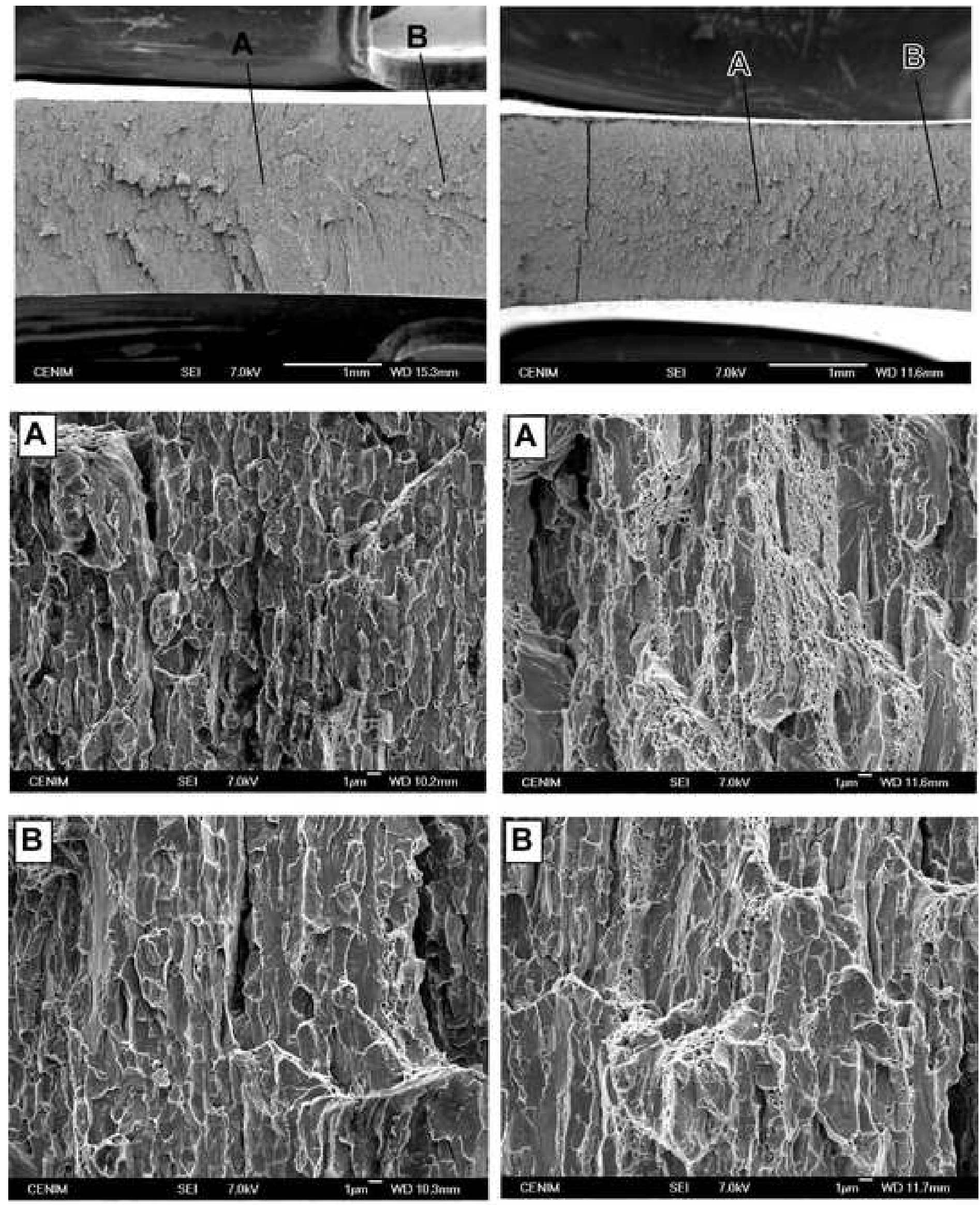


\section{FIGURE LEGENDS}

Figure 1. Optical micrograph of a longitudinal cross section of the as-received material. $\mathrm{X} 1000$.

Figure 2. FEGSEM micrographs showing the microstructure of the material a) Transverse view. b). Longitudinal view.

Figure 3. SEM macrographs showing the necking features of tensile specimens of PM2000 alloy. a) As-received condition $\dot{\varepsilon}=5.10^{-5} \mathrm{~s}^{-1}$. b) As-received condition $\dot{\varepsilon}=5.10^{-}$ ${ }^{2} \mathrm{~s}^{-1}$.c) Aged condition $\dot{\varepsilon}=5.10^{-5} \mathrm{~s}^{-1}$. d) Aged condition $\dot{\varepsilon}=5.10^{-2} \mathrm{~s}^{-1}$

Figure 4. Evolution in longitudinal specimens of PM 2000 alloy of the average axial $\left(\sigma_{\mathrm{zz}}\right)$ stress, the radial $\left(\sigma_{\mathrm{rr}}\right)$ stress, and the hydrostatic $\left(\sigma_{\mathrm{h}}\right)$ stress components at $\mathrm{z}=\mathrm{r}=0$ during deformation and necking. $\mathrm{z}=0$ is the location of minimum cross section of necking and $\mathrm{r}=0$ is the axis of tensile specimen. $\mathrm{A}_{\mathrm{o}}$ and $\mathrm{A}$ are the initial and actual cross section areas of specimen during tensile test. $\dot{\varepsilon}=5 \cdot 10^{-5} \mathrm{~s}^{-1}$ a) As-received condition. b) Aged condition

Figure 5. SEM macrographs showing the necking features of tensile specimens of as received MA 956 alloy. a) $\dot{\varepsilon}=5.10^{-5} \mathrm{~s}^{-1}$. b) $\dot{\varepsilon}=5.10^{-2} \mathrm{~s}^{-1}$.

Figure 6. SEM macrographs showing the necking features of tensile specimens of recrystallised MA956 alloy. a) $\dot{\varepsilon}=5.10^{-5} \mathrm{~s}^{-1}$. b) $\dot{\varepsilon}=5.10^{-2} \mathrm{~s}^{-1}$.

Figure 7. FEGSEM micrographs showing: (a) the profile of the delamination (b) the surface aspect of the delamination.

Figure 8. A broken tensile specimen of PM 2000 alloy aged at $475^{\circ} \mathrm{C}$ for $100 \mathrm{~h}$ : a) Macroscopic view of the delamination surface (b) SEM micrograph showing a detail of as the splitting starts about the centre of the necked cross section.

Figure 9. FEGSEM micrographs showing the fracture surface of transverse specimens of as-received PM2000 alloy. a) $\dot{\varepsilon}=5.10^{-5} \mathrm{~s}^{-1}$ b) $\dot{\varepsilon}=5.10^{-2} \mathrm{~s}^{-1}$

Figure 10. FEGSEM micrographs showing the fracture surface of transverse specimens of PM2000 alloy aged at $475^{\circ} \mathrm{C}$ for $100 \mathrm{~h}$. a) $\dot{\varepsilon}=5.10^{-5} \mathrm{~s}^{-1}$ b) $\dot{\varepsilon}=5.10^{-2} \mathrm{~s}^{-1}$ 

Table I. Chemical composition of PM2000 and MA956 alloys

\begin{tabular}{|c|c|c|c|c|c|c|c|c|}
\hline \multirow{2}{*}{\multicolumn{2}{|c|}{ Material }} & \multicolumn{7}{|c|}{ Chemical Composition wt $\%$} \\
\hline & & $\mathrm{C}$ & $\mathrm{Si}$ & $\mathrm{Mn}$ & $\mathrm{P}$ & $\mathrm{S}$ & $\mathrm{Cr}$ & $\mathrm{Al}$ \\
\hline \multicolumn{2}{|c|}{ PM2000 } & $<0.01$ & $0.09_{5} \quad($ & $0.03_{7}<$ & 0.02 & $<0.005$ & $18.6 \pm 0.08$ & $\overline{5.25 \pm 0.1}$ \\
\hline \multicolumn{2}{|c|}{ MA956 } & 0.012 & 0.12 & 0.097 & $<0.02$ & 0.007 & $19.33 \pm 0.08$ & $4.7 \pm 0.1$ \\
\hline $\mathrm{Ti}$ & $\mathrm{V}$ & Co & $\mathrm{Ni}$ & $\mathrm{Cu}$ & & $\mathrm{O}$ & $\mathrm{N}$ & $\mathrm{Y}_{2} \mathrm{O}_{3}(*)$ \\
\hline $0.5_{4}$ & -- & $0.03_{9}$ & 0.03 & $0.01_{5}$ & 0.0 & $1 \pm 0.02$ & $0.006 \pm 0.011$ & 0.5 \\
\hline 0.012 & 0.12 & 0.097 & $<0.02$ & 0.007 & $7 \quad 0.1$ & $8 \pm 0.015$ & $0.046 \pm 0.003$ & 0.5 \\
\hline
\end{tabular}

(*) Nominal composition

Table II Yield strength, $\sigma_{0.2}$, ultimate tensile strength, UTS, uniform elongation, $\varepsilon_{\text {unif, }}$ total elongation, $\varepsilon$, reduction in area, RA, in the longitudinal, L, and transverse, T, direction of PM2000 alloy at $5.10^{-5} \mathrm{~s}^{-1} / 5.10^{-2} \mathrm{~s}^{-1}$ strain rates.

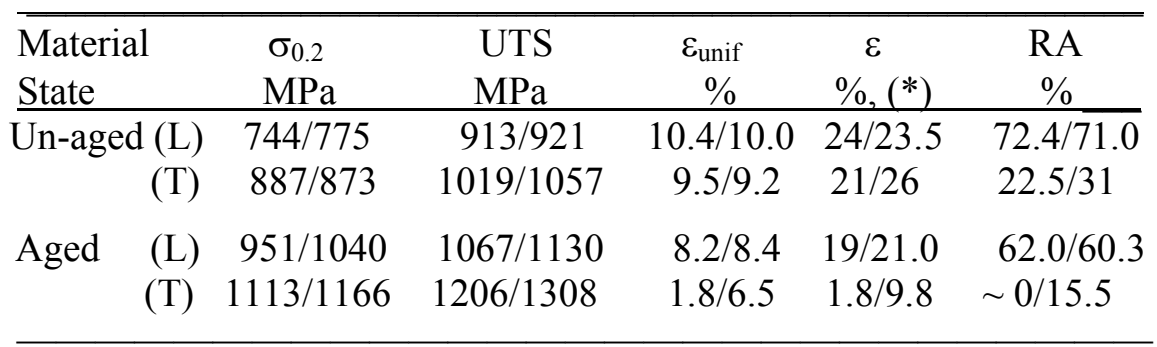

(*) In the longitudinal direction the slimness ratio $\left(L_{o} / \sqrt{S_{o}}\right)$ of the specimen was 5.65 while in the transversal direction was of 2.5 . 
Table III Yield strength, $\sigma_{0.2}$, ultimate tensile strength, UTS, uniform elongation, $\varepsilon_{\text {unif, }}$ total elongation, $\varepsilon$, reduction in area, RA, in the longitudinal of MA956 alloy at $5.10^{-5} \mathrm{~s}^{-1} / 5 \cdot 10^{-2} \mathrm{~s}^{-1}$ strain rates.

\begin{tabular}{lccccc}
\hline Material & $\sigma_{0.2}$ & $\mathrm{UTS}$ & $\varepsilon_{\text {unif }}$ & $\varepsilon$ & $\mathrm{RA}$ \\
State & $\mathrm{MPa}$ & $\mathrm{MPa}$ & $\%$ & $\%$ & $\%$ \\
\hline As-received & $860 / 875$ & $1020 / 1110$ & $9.5 / 8.5$ & $20.8 / 16.5$ & $60.2 / 57.1$ \\
Recrystallized & $561 / 685$ & $600 / 781$ & $8.2 / 8.4$ & $19 / 5.8$ & $38.1 / 28.1$ \\
& & & & & \\
\hline
\end{tabular}

Table IV. Hydrogen content (wppm) of PM2000 and MA956 alloys.

$$
\begin{array}{cc}
\text { PM } 2000 \mid \text { (as-received) } & : 11.0 \pm 2.1 \\
\mid+1100^{\circ} \mathrm{C} / 100 \mathrm{~h} & : 7.4 \pm 3.5 \\
\mid+1100^{\circ} \mathrm{C} / 100 \mathrm{~h}+475^{\circ} \mathrm{C} / 100 \mathrm{~h} & : 6.0 \pm 3.7 \\
& \\
\text { MA } 956 \mid \text { (as-received) } & : 11.0 \pm 2.6 \\
\mid \text { Recrystallized } 1330^{\circ} \mathrm{C} / 1 \mathrm{~h} & : 6.9 \pm 2.1
\end{array}
$$

